\title{
Analysis on the Development Path of Chinese Film Industry from the Perspective of Cooperation-competition
}

\author{
Jianxun $\mathrm{Wu}^{1, \mathrm{a}}$ and Jing $\mathrm{Yi}^{2, \mathrm{~b}}$ \\ ${ }^{1}$ Beijing Film Academy, China \\ ${ }^{2}$ Beijing Film Academy, China \\ awujianxunbfa@outlook.com, byijing_1994@126.com
}

Keywords: Cooperation-competition strategy; Film industry; Development path

\begin{abstract}
Chinese film industry is in a period of rapid development, during the development process it is not only facing the impact of Hollywood and other foreign film industry, but also facing the snatch of market by variety domestic cross-border capital, as well as the existence of the fierce competition of film market itself. In this situation, the Chinese film industry needs to strengthen the core competitiveness through competing ways, through the cooperation-competition to achieve optimal development. This paper briefly describes the development path of the Chinese film industry from the perspective of cooperation-competition strategy, aiming at helping the Chinese film industry to develop benignly.
\end{abstract}

\section{What is The Cooperation-competition Strategy}

Before the 1980s, competition and cooperation were two concepts that were treated and studied separately. Competition was aimed at defeating opponents for maximum benefit, and cooperation was based on the principle of maximizing overall efficiency. Until 1989, Ranmond - Noorda first put forward the concept of "cooperation-competition", he believes that cooperation-competition is beyond the rules of competition and cooperation, it is one of a strategy that could be able to gaining the advantages of competition and cooperation at the same time. In 1996, Brandenburgerhe Nalebuff published the book "Cooperative Competition", which is the beginning of the theory of cooperation-competition. They believe that cooperation-competition is the two aspects of the same relationship, is a new type of inter-firm relations, they point out that game theory is the main method of making a cooperation-competition strategy. When the enterprises aim to open up the market and create value, then the enterprise become the main body of the market activities, enterprises should choose cooperation between consumers, upstream and downstream enterprises, competitors, complementor; when aim to division of market share and distribution of value, the enterprise should choose competitive. Since then, cooperation-competition as a new paradigm of development become the third concept coexistence with the competition and cooperation.

In the 21st century Chinese scholars also have a certain study of cooperation-competition.Bo Wang(2000) studied the advantages of competitive cooperation and the strategic choice of enterprise competition, he pointed out that enterprise cooperation-competition is the inevitable trend of enterprise development, cooperation-competition is conducive to enterprises to optimize the allocation of resources, reduce business risk, reduce production and operation costs, to play their respective advantages, help enterprises to build brand and technological innovation, improving product competitiveness and expand the market size, thereby enhancing business performance. Qingming He and Liping Dai(2004) stand in the perspective of game theory, think that the formation process of enterprise cooperation-competition strategy is a non-zero cooperative game mechanism which can obtain the optimal solution of Pareto, which can help enterprises to maximize profits in the long run.

In short, " Cooperation-competition " is a new type of development relationship, this relationship is neither a "double lose" due to competition, nor a "lose-win" due to concessions, but a non-zero-sum game that can achieve "win-win". In this relationship, competitors from a simple fight against competition to a certain degree of cooperation, cooperation in the competition, 
competition in the competition.

\section{Why Should the film Industry Need Cooperation-competition}

\subsection{The Situation of Chinese Film Market}

China has become the world's most active and the fastest growing film market. China's film box office revenue has grown from 3.13 billion US dollars to about 7.1 billion US dollars during 2013-2016, the box office doubled in four years, and the average annual growth rate is still maintained at around 30\%,In 2016 the Chinese film market grew by 3.76\%; while the American box office growth by $2.2 \%$.. Which shows that Chinese film industry has a great development prospects. With the increasing of film production and the expansion of box office capacity, theater construction throughout the country is also in full swing. The number of screen is 1923 in 2003, which grew to 4.12 million in 2006, Chinese film market has added 9552 new screens during 2016. The explosive growth of number of cinemas and screens laid a good foundation for the development of the Chinese film market. Over the past decade, the Chinese film industry has achieved successful results, however we need to know that there is still a big gap between the Chinese film industry and the world's leading countries neither in film industry chain investment, production, distribution, screening nor derivatives development. Compared to the developed areas Chinese film industry's competitiveness is still limited. Cooperation-competition strategy may one of the ways that can achieve transformation and upgrading.

\subsection{The threat of Chinese film industry during the development}

With the rapid development of Chinese film market, it's also facing various threats. On the one hand, the competition of Europe and American on the Chinese market is more intense; On the other hand, domestic film companies are lack of competitiveness in the creative, industrial operation maturity, late derivatives development etc. At the same time all kinds of cross-border resources began to pour into the film industry. Chinese film industry still have a lot of shortcomings need to be improved to enhance their competitiveness.

2.2.1 Market internationalization led to foreign films to seize the domestic market

At present, the US film industry is already mature enough, the domestic income structure remained stable. As a global leader in the film industry, the value of the film has been to maximize the mining, the box office revenue in the US film industry accounted for $20 \%-30 \%$ of total domestic income, nearly $80 \%$ of revenue come from the expansion of the window and derivatives income. At the same time, the Hollywood film is relatively strong on the overseas output, its share in the global film market remains the first, and it also pay great attention on snatching Chinese and other emerging film market. In a memorandum of understanding between China and the United States on the resolution of WTO-related issues in 2012, China has agreed that will increase the number of 14-part budgets beyond the quota of 20 overseas accounts, but must be 3D movies or IMAX Film, and its box office split ratio will also be increased from $13 \%$ to $25 \%$. The agreement will bring billions of dollars in revenue per year for the US film industry. It is not difficult to imagine that with the maturity of the memorandum of understanding, the signing of a new round of negotiations and agreements will inevitably lead to the opening of the Chinese film market, the Chinese film market in the future will face more impact of Hollywood. In contrast, the Chinese film market is still in the stage of developing, Chinese film industry is experiencing a similar period of transformation as Hollywood in the 1950s and 1960s characterized by the reconstruction of the film industry system, from an integrated, studio system, to a decentralized, flexible, independent and specialized industrial system. However which can't be ignored is that our film market income is still overly dependent on the box office, the development of derivative industry chain is still unable to effectively link.

For the Chinese film company, they can only maintain the defensive situation when facing the impact of the Hollywood film industry currently. On the one hand make efforts to learn from Hollywood's advanced technology and experience to improve own competitiveness; On the other hand try to speed up the development of our own industrial chain, and strive to broaden the length 
of the industrial chain to enhance the industrial chain operation accuracy. Overall, the Chinese film companies is a willing to cooperate with Hollywood film business than competition, hoping to learn advanced ideas to enhance themselves, but will still keep against Hollywood. And the other hand, the US film business take the initiative to enter China for the huge film market, its competition means greater than the cooperation means. Hollywood film companies can't be completely accessible to the Chinese market due to some policy restriction, they need to cooperate with the Chinese film companies to open the door to the Chinese market, so cooperation also in this context. But it is undeniable that the Hollywood film companies are more competitive than the Chinese film companies.

\subsubsection{Industrial extensive development led to weak domestic enterprises competitiveness}

Compared to the US film industry, Chinese film industry is still in an extensive stage of development. There have a large number of enterprises in this industry, and leading enterprises' business involves a wide range film industry chain, large enterprises have strong competition on small and medium enterprises. First of all, based on the definition of traditional film industry chain(production, distribution, screening), the current film industry can be divided into the following types of enterprises: full-function enterprise, multi-function enterprise and single-function enterprise. Full-function enterprise refers to those enterprises contain all 3 sections of traditional film industry chain; Multi-function enterprise refers to those enterprises contain 2 sections of traditional film industry chain; Single-function enterprise only have 1 part of traditional film industry chain. The strong and weak relationship can be significantly contrast from the industrial chain link between the three types. Enterprises are more competitive when occupies more function, and multi-function enterprise and single-function enterprise development path is followed by upgrades.

Due to the existence of full-function enterprise, the degree of competition within the film industry is greater than cooperation. Full-function enterprise have more resources, then will have more advantages for the industry chain convergence, the industrial operation is more smooth compared to multi-function enterprise and single-function enterprise, which cause full-function enterprise have a larger market space. Single-function and multi-function enterprise need to find their own unique advantages, and strive to establish a special competitive in their own market space.It's obvious that the Chinese film industry within the cooperation-competition situation is generally the full- function enterprise's competition is greater than cooperation; Relative to single-function enterprise the multi-function enterprise is in a cooperation-competition state, in order to make up for their gaps in the industry chain multi-function enterprise need to seek an advantage of the single-function enterprise to complement each other, through cooperation to deal with the full- function enterprise's market squeeze, at the same time, multi-function enterprise need to maintain a certain degree of competition to prevent single-function enterprise to grow to seize their market share; Single-function enterprise is completely in a relative disadvantage, they have to both specializes in their own areas and seek full-function and multi-function enterprise's cooperation in order to develop(Figure1).

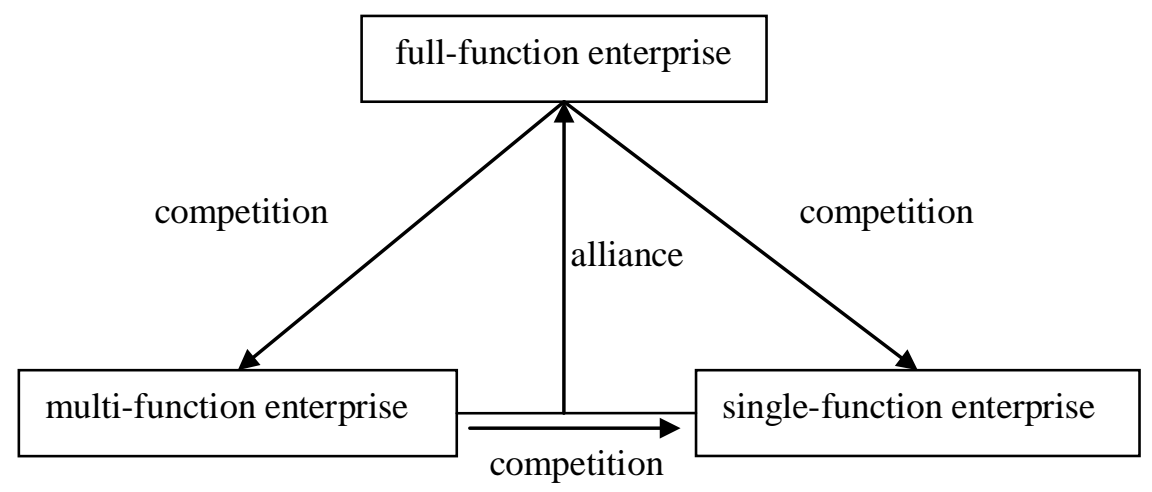

Fig 1.relationship of 3 types of enterprise 


\subsubsection{The decline in barriers led to more intense cross-border competition}

With the developing of film industry, more and more companies in other industries began to enter the film industry, the most typical in Chinese film industry is the Internet giant Baidu, Alibaba, Tencent began to get involved in the film industry. Cross-border enterprises participating in the film industry competition though led the diversity of the film industry, broaden the thinking space of the film industry development, but increased the competitiveness of the film industry, the film industry enterprises will face more intense market competition. In this complex situation, the film industry need to find a way of cooperation-competition.

The prerequisite of those cross-border enterprises entering the film industry is that in the original industry they already have a certain market position, they hoping to enter the film industry to expand their business coverage, and obtain profits or reputation. Such enterprises will carry some of its original industry's effective resources into the film industry, which is a threat for the traditional film enterprises. As the Internet companies to enter the film industry, they will use the Internet channels more flexible and efficient than traditional film companies. The influx of new resources has put pressure on the traditional film enterprises, they have to make up for the relative disadvantage of resources through their familiarity of the industrial chain, and to improve their own soft power by continuous learning. At the same time, cross-border enterprises will choose to join with the film companies, through the mutual complementarity of the two sides to develop the film market, which is a mainstream trend of cooperation-competition among the film industry cross-border competition.

\section{How to Realize Cooperation-competition in China 's Film Industry}

\subsection{Deepen cooperation with the film developed countries to improve the competitiveness of the industry}

In order to cope with the external impact better, the Chinese film industry needs to deepen cooperation with advanced countries, not only for learning foreign advanced concepts and technology but also for opening the foreign film market through cooperation At present, the cooperation is mainly in the form of investment by Chinese companies, so there will have some problems such as lack of project control, shallow understanding of core content, difficult of learning etc. In this case, the improvement of Chinese film industry is limited. We need to find deeper cooperation, especially in our relatively weak links to cooperate, such as derivatives development.

Compared to the Hollywood's competition, the relationship between Chinese film industry and other countries is still in the primary stage. Cooperation with these national films will be able to form a strategic alliance to jointly deal with the impact of Hollywood in the United States. This cooperation can also promote cultural exchanges between each other and expand the integration of film culture. Therefore, the Chinese film industry and other countries film industry is a kind of situation that cooperation is greater than competition.

\subsection{Deepening the cooperation of domestic film companies to enhance the competitiveness of enterprises}

Enhancing the strength of domestic film enterprises is also one of the means to improve the competitiveness of Chinese film industry. But the distribution of the strength of Chinese film industry is more disparity, large enterprises have a strong ability of control the market, small business development space is limited. In this environment, large enterprises can carry out strong combination, small and medium enterprises could try business alliance that is more feasible state of cooperation-competition. Large enterprises through cooperation can achieve the advantages of complementary resources, and also can form the Chinese Film Industry Alliance to deal with the impact of Hollywood. The purpose of the Union between Small and medium-sized enterprises is to response to market shocks better, through the unity of the interests of the target to jointly cope with market competition, compared to a single enterprise competition, the alliance's competitiveness is stronger. For example, in 2014, Wanda Film and Television Media Co., Ltd., the Earth Times Film Co., Ltd., Guangzhou Jinyi Film and Television Co., Ltd., Hengdian cinema line Co., Ltd. reached a joint cooperation of establishing Wuzhou Film Distribution Co., Ltd. During the Shanghai Film 
Festival in 2015, Shanghai Film Group Co., Ltd. and Zhejiang Times Film World Co., Ltd., Jiangsu happy blue sea cinema line, Henan Oscar cinema, Sichuan film company together to form a "universal film distribution alliance."This cinema cooperation is to deal with the requirements of the distribution and production companies' rising box office. This also for respond to market competition better, through cooperation to complete the market share of the competition and strengthen their own strength.

\subsection{Integration of cross-border resources to enhance the industry's own defensive ability}

In addition to the deal with competition from peer practitioners, the film industry's companies also need to focus on competition from other industry entrants. For example, Tencent set up Tencent Film Co., Ltd. and Penguin Film Co., Ltd., Ali set up Ali Film Co., Ltd., these Internet companies will began to use their own resources to affect the film industry. In this situation, the film companies need to engage in cross-border integration actively, using their familiarity of film industry to make cooperation with the cross-border resources, through cooperation to develop film projects, and avoid the positive conflict with cross-border enterprises, and ultimately achieve win-win situation. For example, Wanda and the time network cooperation, hoping to achieve win-win situation in the film derivatives, film promotion and line theater convergence.

\section{Conclusion}

Cooperation-competition strategy is a approach that pursuit of win-win development, this can minimize the loss brought by competition, through the model of $1+1>2$ to increase the development of the internal power, through the sharing of resources, information exchange to achieve a reasonable resources allocation. Chinese film industry is still in a period of rapid development, compared to Hollywood's mature film industry system we still have lots of insufficient. It is an effective way for Chinese film industry to continue to develop through cooperation-competition including quick learning of Hollywood experience, improve industry and enterprise competitiveness.

\section{Acknowledgement}

In this paper, the research was sponsored by the National Social Science Fund of China (Project No. 16ZD04).

\section{References}

[1] Yadong Lu, Jinyun Sun. A New Perspective of Chinese Enterprises' Growth Strategy: Concept, Connotation and Method of Compound Foundation View [J]. Management World, 2015 (10) 106-117.

[2] The Combination of Chinese Film Industry Development Under Full Media Age [J]. Journal of Beijing Film Academy, 2015(1). 156-159.

[3] Shuguang Rao,Jia Xian. "Internet +" And the Promotion of Chinese Film [J]. Contemporary Cinema, 2015 (7) 6-10.

[4] Yi Zhao. Constructing the Model of Chinese Film Industry in the New Media Age [J]. New Films, 2015 (1) 9-12. 